was under the influence of an anæsthetic stretching the sphincter ani with the forefingers introduced back to back sufficiently forcibly to paralyse it for a time and allow the sore produced by the snipping off of the pile to heal; in the same way as one would cure a fissure of the anus, by setting the spasm of the sphincter ani at rest, which, constantly contracting, might possibly be an element, through reflex action, in helping to keep up the vesical irritability.

Accordingly, on March 5th, chloroform having been administered, I completely carried out the above suggestions. The result of this was, that during the next few weeks relief was given to the retention of urine and to the pain in passing the motions; but there was no relief at all from the vesical irritability. Her general condition, with these exceptions, continued as before, and there was a return of the retention of urine at the end of three weeks from the operation.

I had clearly told her a second operation would possibly be necessary should the first fail to give relief, and accordingly, on April 11th, I again placed her under the influence of chloroform, and introducing Weiss's female dilator in to the urethra to the extent of about two inches, I then slowly separated the blades of the dilator, stretching the urethra so as to admit of the introduction of $m y$ forefingers within the bladder while the parts were on the stretch. On closing the blades and withdrawing the instrument, the urethra contracted upon my little finger, so as sensibly to grip it when introduced into the bladder, the coats of which were thickened. There was no foreign body or stone to be detected.

She was very much upset by the chloroform-sickness, which continued more or less all night; there was, bowever, no more irritability of the bladder, no retention, no incontinence produced, and, to use her own words, "I have not passed water so freely for years"; nor had she retained it so long without being disturbed, for the first time she made water was in the evening after the operation, and she was not disturbed daring the whole night.

April 14th.- She slept the night through, and awoke with little or no headache, retaining and passing her water quite naturally with the exception of some soreness.

16th.-She complains of slight pain while passing water, but perfect facility.

19th.-She got up in the evening complaining of none of her former symptoms, having lost completely all trace of vesical irritability in eight days from the dilatation of the urethra.

Her progress now continued to be satisfactory and very rapid.

May 4th.-She reports her old symptoms to have all disappeared. She sleeps and eats well, and takes a fair amount of exercise.

At this stage I ordered her into the country, where she resides, and returning on May 31st, she reported herself as perfectly well, and has gained three stones in weight. On the day previously she had walked a distance of eight miles without feeling more than ordinary fatigue, and remarked that before the operation "she could hardly trail herself about."”

Thus, then, were the miserable and intractable sufferings of years, shutting out this poor woman alike from society and employment, put an end to at once by an operation whose best recommendation is its simplicity and its success. Leeds.

\section{CASE OF HIGH TEMPERATURE IN RHEU. MATIC FEVER TREATED WITH THE WET PACK.}

BY T. CARLETON RAILTON, M.B.LOND., F.R.C.S. ENG.

ELLEN G—, aged twenty, a housemaid, after having complained for two days of not feeling very well, and of pain in her right wrist, was sent to bed on June 25th, 1874, with all the symptoms of rheumatic fever. The pulse was 100 , full and soft; both wrists were painful, and slightly swollen, and there was a copious perspiration, having the usual sour odour. The only treatment adopted at this stage was an opiate mixture to relieve the pain, together with the wrapping up of the affected joints in cotton wadding.
On June 26th the pain in the wrists had become more severe, and was accompanied by pain in one knee and in the back. The temperature taken at $10 \mathrm{~A}$.M., in the axilla, was $102^{\circ} \mathrm{F}$. Upon auscultating the chest, a mitral reyurgitant murmur, soft in character, was perceived; this was treated hy the application of one of Rigollot's inustard Jeaves over the cardiac region, followed by a constant succession of hot linseed-meal poultices.

June 28th. -The pain in the jnints, although diminished in the wrists, had become intensified elsewhere, both knees and one ankle being somewhat swollen. Since the 26 th the mustard leaves had been reapplied to the chest as frequently as the patient could bear them.

29 th. - On being raised up in bed the patient fainted. The pulse still remained 100, but was very soft and compressible. A freshly prepared infusion of digitalis was ordered, together with certain fixed quantities of nourishment and stimulants at frequent intervals.

30 th. - The faintness still continued; other symptoms remained the same.

July 1st.-The same symptoms. Temperature at 7 P.M. $103^{\circ}$. At night she began to ramble in her speech. Cold water cloths were kept constantly applied to her head.

2nd.-Rambling continued. Ice to the head.

3rd.-The rambling had turned to loud delirium, the carotids beating fiercely. The temperature at 4.30 P.M. being found to reach $105 \cdot 7^{\circ}$, the wet pack was resorted to for the first time. A sheet was soaked in iced water and wrung out; the patient was then enveloped in it from head to foot for the space of half an hour, at the end of which period the thermometer showed an abatement of the temperature to $104^{\circ}$, and so far from appearing exhausted by the process the patient appeared considerably improved; the pulse, though still 100, being firmer, while the violent excitement had given way to a comparatively sound sleep. At 11 o'clock the same evening these good effects had passed off, but the temperature still continued at $101^{\circ}$. The wet pack was applied for the second time in the same way as before, with the result of a descent in temperature to $102^{\circ}$ and a tolerably quiet night.

4th.-At 10 A.m. the temperature had again risen to $104.5^{\circ}$, and the patient still continued to ramble. After another half hour in the wet pack, the temperature went down to $1018^{\circ}$; pulse 100; respiration 28. At 11 P.M. I was hastily sent for. The woman appeared to be sinking and almost unconscious; the pulse was very rapid and weak; the tem perature was 104: $2^{\circ}$. So great was the bodily prostration that I feared to have her lifted from the bed to the couch upon which the wet sheet had been spread, therefore, as an alternative plan, a large bath towel wrung out of iced water was tucked around her as far as possible without disturbing her. Stimulants and beef-tea were constantly administered. At the end of fire minutes the towel was changed for a freshly-iced one, and in five minutes more a third was applied, the whole process thus occupying the space of a quarter of an hour, with the result of a descent in temperature to $103.4^{\circ}$, and a pulse much firmer and slower.

5tb.-At 2 A.M. the bath towels were again applied as before to the front of the body, reducing the temperaturo to $102^{\circ}$. At 4 A.M. the process was repeated, but without observation as to the temperature. The patient was afterwards sponged over slowly with iced water from head to foot at intervals of an hour until 11 A.M., and by this means the temperature was maintained at $102^{\circ}$. The pulse (102) at this time was very much firmer, and the patient appeared calmer and more collected than she had been during the previous five days. The ice to the head was discontinued. The sponging was renewed for a quarter of an hour at 7 P.M., and also at 11.45 P.M., at which time the temperature was found to be $101 \cdot 4$.

6 th.-At 9 A $M$. the patient, though still suffering considerable pain in some of her joints, was perfectly composed, and the marked depression from which she had previously suffered had passed off. Her pulse was 92 ; the temperature $100.4^{\circ}$.

Since the last date she gradually but slowly returned to comparative health, with but one slight relapse of the affection of the joints, unaccompanied by any great increase of temperature. The period of convalescence was naturally prolonged by the existence of the valvular disease of the heart, and by a very severe bedsore, but at the present 
time she is well enough to perform all the ordinary duties of her station.

In this brief record of (what was to $m e$ ) a most interesting case, I have designedly omitted many details, as not bearing directly upon the object $I$ have had in view in reporting it. It is evident that the application of cold to the body in cases where the temperature of the blood rises to a pitch at which it imperils the action of the heart (threatens its paralysis in fact), is as justifiable a course in rheumatic fever as in any other.

Old Trafford, Manchester.

\section{TWO CASES OF THORACIC ANEURISM.}

\section{BY FREDERICK ENSOR, M.R.C.S.,}

SURGHON TO THE PROVINOIAL HOSPITAL, PORT BLIZABHTH, SOUTH APRICA.

To the physician who is alive to the insidious nature of thoracic aneurism, no cases cause more anxiety than those which exbibit symptoms of this grave organic lesion. I imagine in every hospital of seaport towns "cases" from the shipping are admitted which of ten puzzle the keenest and most painstaking observer. Men who are dissatisfied with their ship or captain, or who are attracted by diamondfields or stories from gold-fields, will try every ruse to keep in hospital, but directly the vessel is out of sight their recovery is marvellously quick. When a man tells the usniil tale of having pains here and there, and at the same time his pulse and temperature are fairly normal, or perhaps the former a little quickened by his "intent to deceive," and there be no marked symptoms of rheumatism, or expression of malaria or syphilis, you cannot but suspect him of malingrring; and yet he may be the subject of grave internal mischief, causing immediate danger to life. I always like to give a man the benefit of the donbt, and watch and wait for a few days rather than act on a diagnosis which one may have cause to regret.

From manuscript noles of a clinical lecture on a case of aneurism of the aorta, by Dr. Todd, in 1855, I copy the following: "When patients above the age of thirty come to consult you about pains extending over the shoulders and chest, an aneurism should always be suspected." All King's men who had the good fortune to study disease at the bedside under that master in diagnosis, Dr. Todd, will coincide with me that it was a privilege and a treat to see him grapple with a difficult case of heart disease or aneurism: the repeated careful examination; the appreciation of, to us students, trifling symptoms; the patient watching of the man as he perhaps sat on his bedside; and the feeling that the vim, or vital force, or mind, as his disciple, Dr. Brale, would say, was stirring the depth and breadth of bis "cerebral bioplasm," as it strove to solve the "enigma of life" in question, had a good effect on the class, and I dare say bas made not a few strive to follow in the steps of so great a teacher.

The aid to diagnosis, which I quote from the clinical lecture, has been well illustrated in two cases which have come under my observation in this hospital; one occurred some two year's ago, the other a few days since. As necessity of care in diagnosis is the only point I wish to lay stress on in these cases, I will not enter into much detail.

The first case was that of a sailor-I write from memory. He was a tall man, rather thin, aged about forty, and was admitted complaining of pain, not very severe, of a neuralgic character, in the spine and about the chest. The captain "thought he was echeming." He had been under medical treatment for same symptoms; no diagnosis had been distinctly given; he was suspected of trying to get rid of his ship.

I examined him several times and got at no positive symptoms to guide me, and yet there was something in his look which told of suffering, and made one feel that the man's pains were not imaginary. He had been in hospital about a week when I detected a prolonged sound, not amountiug to a " bruit," at the back, between the shoulders. I gave a guarded diagnosis of aneurism of the thoracic aorta. A few days after, in the act of lighting his pipe, he fell dead at his bedside, and the post-mortem examination disclosed a circumscribed aneurism of the descending aorta, which, having eroded two or three of the vertebræ bad given way and filled the left pleura with blood. When men are admitted who, without a doubt, are "sea lawyers," I generally order a few doses of sulphate of magnesia, flavoured with tincture of assafoetida, and I find that they soon ask permission to leave the house. In the post-mortem room I felt glad I had not ordered the "stimulant mixture," as we term it, in the above case.

The second case, which occurred a few days ago, was the following :-A tall, thin, big-boned man, formerly a private in the German Legion, was admitted complaining of pain lancinating in the line of the intercostal nerves and lower part of the chest. No murmur at base or aper of the heart. Pulse even in both radials; no dulness over the middle of the sternum ; no marked dyspnoea. The only thing I could detect was a limited dulness about the middle of the left lung, with rather harsh respiratory sounds; no cough or expectoration; pulse and temperature normal. The man was, nevertheless, conscious of something serious the matter with him; his eyes 'were particularly bright, the sclerotic pearly and clear.

At first I thought he was a dyspeptic "loafer" trying to remain in hospital. A thought of tubercle being laid down crossed my mind, but the pulse and temperature were against this idea. I remarked to the house-surgeon, " that it was not improbable we should find an aneurism in this case." After a careful examination, 1 could come to no conclusion, refused to commit myself to a diagnosis, and simply ordered him to remain in bed. No medicine was prescribed.

Two days after this, while engaged in an operation for crushed foot, the nurse entered the room, saying the German was "in a fit," as she called it. As soon as the operation was completed, on proceeding to the ward, I saw the poor fellow lying in bed, quite dead, with extreme pallor on his face. He had evidently died in a faint. The following day a post-mortem examination revealed an aneurism about the size of a turkey's egg in the descending aorta, which had eroded the seventh and eighth vertebræ, and had burst, filling the pleura with blood. The heart was small, and thin and pale in its muscular structure. The aortic valves were somewhat thickened, but not incomplete; the mitral valve was also thickened a little, but, I imagine, had been equal to its office, or we should have had more dyspnœa. Both lungs were byperæmic, the left slightly consolidated at its contact with the aneurism.

These two cases illustrate well how cantions one should be in coming to a conclusion in a case. A harsh judgment, a wrong diagnosis followed by harmful treatment, would always be a matter of extreme regret to the physician, and, in some cases, might give rise to much social distress. Better that a scheming patient should impose on his doctor for a few days than that a poor fellow with thoracic aneuriam should be hurried to his end by active treatment on a wrong diagnosis.

In Trousseau's "Clinical Medicine," vol. i., p. 597, is a case well illustrating the point $I$ wish to impress in these few remarks.

\section{DIABETES MELLITUS OR GLYCOH AMIA. \\ CASE OF}

Bx SuRgeon JOHN C. LUCAS,

F.M. BOMBAT ARMY; IN MEDTCAL CHARGE H.M. 18TH REGIMTKT, N.I., CAMP DEHSA.

Private Punchum lalla, aged forky; service twenty years; married, but no family. The patient, a man of average height and fair intelligence, says that he enjoyed excellent health until about eighteen months ago, when, serving with the regiment at Rajcote, after repeated attacks of fever and ague, he observed that he began to pass large quantities of urine, and that the calls to micturition had been increasing in frequency, and also thirst had been in proportion excessive. His appetite has been gradually augmenting, and now he describes it to be ravenous. He has been rapidly losing flesh; from being a strong, muscular man, he is reduced almost to a skeleton. He complains of dimness of vision and near-sightedness, which he says have been steadily advancing. He admits having contracted a 